\title{
Clinical confidence following an interprofessional educational program on eating disorders for health care professionals: a qualitative analysis
}

This article was published in the following Dove Press journal:

Journal of Multidisciplinary Healthcare

10 August 2012

Number of times this article has been viewed

\author{
Gunn Pettersen' \\ Jan H Rosenvinge' \\ Kari-Brith Thune-Larsen ${ }^{2}$ \\ Rolf Wynn ${ }^{1,3}$ \\ 'Faculty of Health Sciences, University \\ of Troms $\varnothing$, Troms $\varnothing$, Norway; ${ }^{2}$ Oslo \\ University Hospital, Oslo, Norway; \\ ${ }^{3}$ Division of Addictions and Specialized \\ Services, University Hospital of North \\ Norway, Tromsø, Norway
}

Correspondence: Gunn Pettersen Faculty of Health Sciences, University of Tromsø, Tromsø, Norway Email gunn.pettersen@uit.no

\begin{abstract}
There are an increasing number of educational programs to improve clinical competence and skills to treat mental disorders. For complex disorders there is also a focus on improving the quality of interprofessional work. This paper reports on interprofessional outputs of an educational program on eating disorders. A total of 207 professionals who completed the program were requested to describe up to 12 possible scenarios depicted as realistic prospects for their future work within this field. Analyzing the scenarios resulted in three categories of describing the participants' preferences: (1) interprofessional interventions and treatment; (2) the further development of competence; and (3) organization of the health care system. The findings showed that the participants were considering working across new lines in their current workplaces or crossing borders to new frontiers in the execution of competence. Our findings may be summarized into the concept of "clinical confidence." This concept has so far been understood as some kind of personal trait, disposition, or attitude. The present findings add nuances to this concept in terms of state-dependent encouragement, engagement, and a potential to act and to cross professional borders in order to better treat complex mental disorders.
\end{abstract}

Keywords: interprofessional educational programs, interprofessional work, clinical confidence, eating disorders program, health care professional

\section{Introduction}

The complex perpetuating mechanisms of many mental disorders may require a multidisciplinary or interprofessional treatment approach, in which many health care professionals collaborate well together, and there is an increasing recognition of the need for good interprofessional teamwork to treat complex disorders. ${ }^{1,2}$ Eating disorders serve as an example of successful treatment often requiring interprofessional collaboration. ${ }^{3}$ In addition to addressing disorder complexity, another purpose of an interprofessional approach is to establish "system-based competence." Such competence is manifested as operative and functional clinical routines and procedures in a particular context (eg, within a hospital or across a number of collaborating units), and where the competence (ie, the functionality) is facilitated, but not dependent on the presence and competence of particular professionals. By contrast, individual-based competence depends on a particular health care professional who takes a special interest in treating a given illness. Services provided according to an individual-based competence may be poorly suited to complex illnesses. Moreover, services resting on such individual-based competence may be vulnerable to professional migration and turnover, increasing the risk of fragmentation or instability of treatment services. 
As a result of recognizing the needs and benefits of addressing the complexity of disorders through stable professional platforms, an increasing number of interprofessional educational programs (IPE) have been developed, ${ }^{4-6}$ and there is a growing interest among students and professionals in participating in such programs. The present study focuses on an IPE program developed in Norway for clinicians working with eating disorders.

Evaluation of IPE programs is often intended to capture patient benefit, individual clinical attitudes, change in organizational practice, competence about a given disease, or clinical procedures and the understanding of interprofessional work through interprofessional learning. ${ }^{5-11}$ To our knowledge, no studies have investigated IPE-participants' post-program future practice intentions to continue taking an interprofessional perspective. In the present study we thus focus on the program participants' inspirations for future interprofessional work using a qualitative approach. Such an approach has been strongly advocated ${ }^{12}$ in order to make progress in understanding how to promote interprofessional work.

\section{Outline of the IPE program}

Funded by the Norwegian Ministry of Health, the program Body and Self-Esteem started up in 1998. It has two aims: to address health professionals' needs for comprehensive clinical competence, and to increase professionals' understanding of the potential and actual benefits of working interprofessionally to treat eating disorders. To date, nearly 15 years later, about 800 nurses, psychologists, medical doctors, and health care workers have completed the program.

Each class runs for 18 months and consists of about 40 participants, and a total of about 150 participants per year are enrolled on a national basis. The program consists of plenary lectures (11 days), and 48 hours' clinical supervision in smaller groups of 7-8 participants. At least one-third of the participants are recruited from the primary health care services. In general, applicants are selected based on a combination of individual motivation and a potential for local network group dissemination. The program addresses the integration of factual knowledge (plenary lectures) about the nature of eating disorders, aspects of prevention and treatment, as well as how to manage challenges explored through the participants' own clinical cases (supervision groups). Moreover, the supervision groups are composed to represent various health care professionals working within the same local district and to stimulate interprofessional work in terms of (for instance) building local professional network groups or acting as resource for professionals in their communities. Using a pre-post design, a previous study ${ }^{13}$ has shown a statistically significant increment of clinical competence, thus in accordance with the program purpose. This study also provides a more detailed program description. Using a customary categorization of IPE programs, ${ }^{14}$ our program may be described as "exchange-based."

\section{Method}

\section{Participants}

The first 207 program participants ( 187 women and 20 men) were invited to respond, and all of them completed this part of the evaluation procedure. The mean age was 45.4 years (range 24-60). Forty-six participants were working in primary health care and 129 were working in the secondary health care sector. The remaining 32 health care workers did not provide detailed information about their current workplace. Occupationally, 97 were nurses, 31 were medical doctors, 30 were psychologists, 42 had other kinds of occupations in the health care system, six participants did not work within health care, and one failed to state his or her occupation. The participants reported working clinically with a mean of five eating disorder patients during the past 12 months before this investigation.

\section{Open questionnaire}

As a part of the evaluation procedure, we requested that the participants describe up to 12 future practice intentions in a free text at the end of the IPE program. Participants were asked to describe their intentions in terms of scenarios that they depicted as realistic in their future engagement in the management of eating disorder patients or in the organization of services within the field of eating disorders.

\section{Data analysis}

This study used an explorative and descriptive design, in which content analysis ${ }^{15}$ was used to search for contexts, meanings, interpretations, and consequences. In total, 903 quotations were obtained from the 207 participants.

All the texts were read in order to obtain an overall picture of the main themes. The next step was coding, where additional notes on the themes and ideas that emerged were made during the reading of the texts, and topics were identified to form the primary broad categories. The analysis then continued with a further reading of the texts to filter out irrelevant information and identify nuances in the broad categories. The material was sorted into descriptive meaning 
units based on the aims of the study. The meaning units were condensed in a way so that they were close to the text but shortened in length. In addition, the analysis produced a range of nodes supplementing the category descriptions. To ensure clarity and consistency, the categorizations were independently checked by all three study authors. In the following, extracted quotations are used to illustrate the categories.

\section{Results}

Analyzing and sorting the scenarios provided three categories that described the participants' preferred future working situations within an interprofessional frame: (1) interprofessional interventions and treatment; (2) further development of competence; and (3) organization of the health care system. In the following, we report the actual number of participants who made statements within each category. The sum exceeds the number of participants due to multiple responses.

\section{Category I: interprofessional interventions and treatment}

A total of 138 respondents expressed a strong wish to work interprofessionally. The wish to establish an interdisciplinary team for working with patients was frequently mentioned, as illustrated with the following quotation: "I want to cooperate with a doctor, a psychologist, and a nurse so we can be working as a team with these patients."

The participants were also strongly occupied with starting new services and improving the existing services for eating disorder patients. Many were engaged in becoming a part of an interprofessional team in their own working places. A typical quotation is, "I strongly want to start up group therapy for young girls with eating disorders." New services were comprised of family therapy or family work. Participants also made expressions of having developed the courage to offer psychoeducation and support groups to siblings, and possibly to use the internet as a working tool. Early detection of adolescents with eating disorder symptoms through collaboration across health and educational professions was also central within this category. Working with patient groups with the intention of relapse prevention was another frequently mentioned effort. Some participants wanted to start a private service, and some had ideas about developing a walk-in competence center where sufferers and relatives could seek advice. Included herein was a wish to establish better treatment services to obese people with possible eating disorders. The participants also included research, evaluation of their treatment, and participating in a clinical research network group as important for their future work.

\section{Category 2: the further development of competence}

A total of 166 of the 207 participants expressed a wish to further develop their competence by attending more courses on eating disorders. Two examples of scenarios may illustrate this need: "I want to be educated and to get more competence about structured methods and manuals for use in treatment," and, "I will continue getting more courses, going to conferences and being up-to date with respect to new literature. I want to have more knowledge and experience, enough to feel as a resource person in the eating disorders field."

Yet, the usual and unspecified "plea for more" (knowledge) was the exception. Rather, the structural aspects of the program seemed to attract even more interest than just listening to more lectures. A wish to continue the networking group established in the program was frequently mentioned, as this quotation illustrates: "I want to continue the contact with my supervision group from the program, and to develop this to a 'bank of ideas' for professional development for all the participants." Thus, the structural aspects represented by the continuous and regular supervision during the program were strongly focused; however, the engagement reached further.

Participants wanted to join groups in which one could both give and receive supervision, exemplified by this quotation: "I would like to have the opportunity to get more supervision with difficult cases, but also to have the opportunity to use my knowledge to help others." Thus, participants wanted to continue their original supervision group established during the program, but also to extend the learning arena to many kinds of professional networks where they could discuss cases and receive a multitude of professional input. This is exemplified with the following quotation: "I want to be a part of a professional network in my region. A type of network that can be mobilized by need, a place to seek advice and supervision." This quotation thus illustrates the strong wish to share knowledge with others, but with a proactive touch (eg, "I want to set up courses and supervision groups of school nurses and interdisciplinary groups in the local district"). The wish to educate others included many professions besides one's own, and it could be within in their own workplace or outside - for instance, in terms of offering a university course. A few participants even had ideas about writing books. 


\section{Category 3: organization of the health care system}

Better organization of health care services for eating disorder patients was the common issue within this category. A total of 115 participants reported a wish to promote good cooperation and follow-up within the health care system (ie, an interdisciplinary collaboration between the primary and specialized health care system, for instance in terms of regular clinical supervision). The participants also wanted to be engaged in "organizational work" and implement their knowledge of the field herein, exemplified in the following quote: "I want to use my competence in the planning and organization of the health care service to this patient group."

Thus, the participants wanted to be involved in the planning and establishment of services for eating disorder patients. This use of acquired competence was, however, not always restricted to one's own working place, as this quotation illustrates: "I want to build up a clinical network and competence in somatic units for children in the hospitals in my region and in other hospitals in the country." Working with organizational issues was also associated with influencing political decision makers.

\section{Discussion}

In the present study we investigated the reported preferences with respect to expected realistic future work and professional engagement in the field of eating disorders after completing an IPE program. Meaningful interpretations of the findings show that participants displayed readiness and courage to cross professional boundaries, and thereby to enter new arenas to implement knowledge and competence. This is shown in the participants' wish to set up network groups and resource groups; in their desire to establish routines for early detection; and in their need for locally based education programs for patients, relatives, school teachers, and health care workers. There was a clear interest in collaboration across professional lines. The main topic of interprofessional work may be "working together," and thereby to develop new knowledge and competence that one person could not accomplish alone. ${ }^{16}$ This trend is supported by national surveys of health care services in the field of eating disorders indicating a movement from individual towards more system-based interprofessional and collaborative efforts. ${ }^{17,18}$ The consistency of responding from over 200 participants indicates that they subjectively experienced that the IPE program had inspired them to work interprofessionally and in new professional settings.
"Clinical confidence" may serve as a superscript to our findings. Hence, a confident professional may be defined as an individual who relies on one's competence sufficiently enough to explore new workplaces or contexts in order to put one's competence into practice.

In the literature, ${ }^{19}$ however, "confidence" has been linked to dispositional or trait-dependent aspects like Bandura's term "self-efficacy," or the term "social capital" with allusion to Bourdieu. Following this line of thought, several authors define "confidence" as a certainty that a given professional task or approach will bring about an expected, favorable outcome, ${ }^{20}$ as well as a belief in one's judgment and abilities. ${ }^{21,22}$ In the present study, "clinical confidence" is understood in terms of encouragement and exploration of new professional frontiers. This may represent important new nuances of "confidence" in terms of behavioral outputs or manifestations, which also have been called for by previous authors. ${ }^{22}$ On the other hand, nuances provided by the present study are limited by rather broad categories as a consequence of the fact that the text material consisted of statements rather than an extensive and coherent set of paragraphs.

In the evaluation of IPE programs, knowledge and competence are the traditional output factors. Within the field of mental diseases, a recent review shows that "confidence" as an output parameter has attracted less focus. One reason may be that as far as complex disorders are concerned, challenges in reaching meaningful definitions may become more evident. ${ }^{22}$ It is in this context that measuring "confidence" runs into problems. Self-reporting of perceived confidence is commonplace, ${ }^{23,24}$ yet this methodology suffers from self-estimation biases. ${ }^{20}$ Moreover, measures of confidence may be too genera ${ }^{25-27}$ and they may suffer from poor psychometric quality. ${ }^{20}$ These measures may be better suited for addressing student confidence, or they may be tailored to particular clinical procedures that are not relevant for mental disorders. ${ }^{28,29}$

Obviously "confidence" should develop as a synthesis of knowledge about the complexity of a particular illness and competence in treating the disease. Such a synthesis may guard against uncritical or unrealistic actions that certainly would not be a preferred output from an IPE program. Indeed, our findings suggest a realistic confidence in the sense that participants highlighted a wish to disseminate knowledge and competence tailored to suit local organizations and local needs. Adopting such a local perspective may render plans for improving competence a far better chance of actually being implemented. Moreover, a realistic level of confidence may seem to be a prerequisite for a true interprofessional 
approach based on a mutual acknowledgement of profession based competence.

The development and facilitation of professional confidence and competence, as well as shared values should be nurtured, given that the former underpins the latter, and both are linked to the development of a professional identity. ${ }^{22}$ Future conceptual and empirical studies may hopefully use or develop valid measurements of realistic levels of clinical confidence in order to evaluate IPE programs tailored to complex mental disorders. Valid and reliable evaluation procedures are certainly called for in view of the many negative findings in the literature ${ }^{6}$ with respect to patient benefit and patient outcomes.

\section{Disclosure}

The authors report no conflicts of interest in this work.

\section{References}

1. Carlisle C, Cooper H, Watkins C. "Do none of you talk to each other?": the challenges facing implementation of interprofessional education. Med Teach. 2004;26(6):545-552.

2. McGrath M. Multidisciplinary Teamwork. Avebury: Aldershot; 1991.

3. Cooper H, Carlisle C, Gibbs T, Watkins C. Developing an evidence base for interdisciplinary learning: a systematic review. J Adv Nurs. 2001;35(2):228-237.

4. Rosenvinge JH, Pettersen G. Towards a comprehensive model of recovery. In: JáureguiLobera I, editor. Relevant Topics in Eating Disorders. Rijeka: InTech Publishing House; 2012:169-192.

5. Reeves S, Zwarenstein M, Goldman J, et al. Interprofessional education: effects on professional practice and health care outcomes. Cochrane Database Syst Rev. 2008;1:CD002213.

6. Oandasan I, Reeves S. Key elements of interprofessional education. Part 2: factors, processes and outcomes. J Interprof Care. 2005; 19(Suppl 1):39-48.

7. Baggs JG. Development of an instrument to measure collaboration and satisfaction about care decisions. J Adv Nurs. 1994;20(1):176-182.

8. Luecht RM, Madsen MK, Taugher MP, Petterson BJ. Assessing professional perceptions: design and validation of an Interdisciplinary Education Perception Scale. J Allied Health. 1990;19(2):181-191.

9. Freeth D, Hammick M, Koppel I, Reeves S, Barr H. A Critical Review of Evaluations of Interprofessional Education. London: Centre for the Advancement of Interprofessional Education; 2002.

10. Hyer K, Fairchild S, Abraham I, Mezey M, Fulmer T. Measuring attitudes related to interdisciplinary training: revisiting the Heinemann, Schmitt and Farrell 'attitudes toward health care teams' scale. J Interprof Care. 2000;14(3):249-258.
11. Parsell G, Spalding R, Bligh J. Shared goals, shared learning: evaluation of a multiprofessional course for undergraduate students. Med Educ. 1998;32(3):304-311.

12. Zwarenstein M, Goldman J, Reeves S. Interprofessional collaboration: effects of practice-based interventions on professional practice and healthcare outcomes. Cochrane Database Syst Rev. 2009;3: CD000072.

13. Rosenvinge JH, Skårderud F, Thune-Larsen KB. Can educational programmes raise clinical competence in treating eating disorders? Eur Eat Disord Rev. 2003;11:1-15.

14. Barr H. Ends and means in inter-professional education: towards a typology. Education for Health. 1996;9:341-352.

15. Morse JM, Field PA. Qualitative Research Methods for Health Professionals. Thousand Oaks: Sage; 1995.

16. Rosenvinge JH, Larsen E, Skårderud F, Thune-Larsen KB. Clinical competence, what is it and how can it be acquired? J Norwegian Psychol Ass. 2004;39:706-712.

17. Rosenvinge JH, Pettersen G. Services for patients with eating disorders a national survey. J Norwegian Psychol Ass. 2006;41:1160-1168.

18. Rosenvinge J, Borgen JS. Eating disorders - how is treatment organized? Tidsskr Nor Laegenforen. 1999;119(1):21-23.

19. Hean S, Craddock D, Hammick M. Theoretical insights into interprofessional education. Med Teach. 2012;34(2):158-160.

20. Glidewell JC, Livert DE. Confidence in the practice of clinical psychology. Prof Psychol Res Pr. 1992;23(5):362-368.

21. White KA. Self-confidence: a concept analysis. Nurs Forum. 2009; 44(2):103-114.

22. Holland K, Middleton L, Uys L. Professional confidence: a concept analysis. Scand J Occup Ther. 2012;19(2):214-244.

23. Morgan PJ, Cleave-Hogg D. Comparison between medical students' experience, confidence and competence. Med Educ. 2002;36(6): 534-539.

24. Cushing A. Assessment of non-cognitive factors. In: Norman GR, van der Vleuten DE, Newble DI, editors. International Handbook of Research in Medical Education. Dordrecht Netherlands: Springer; 2002:711-755.

25. Lindqvist S, Duncan A, Shepstone L, Watts F, Pearce S. Development of the 'Attitudes to Health Professionals Questionnaire' (AHPQ): a measure to assess interprofessional attitudes. J Interprof Care. 2005; 19(3):269-279.

26. McFadyen A, Maclaren WM, Webster VS. The Interdisciplinary Education Perception Scale (IEPS): an alternative remodelled sub-scale structure and its reliability. J Interprof Care. 2007;21(4):433-443.

27. Nomura K, Yano E, Fukui T. Gender differences in clinical confidence: a nationwide survey of resident physicians in Japan. Acad Med. 2010; 85(4):647-653.

28. Bell A, Horsfall J, Goodin W. The Mental Health Nursing Clinical Confidence Scale: a tool for measuring undergraduate learning on mental health clinical placements. Aust NZJ Ment Health Nurs. 1998; 7(4):184-190.

29. Smith M, Lennon MA, Brook AH, Robinson PG. A randomized controlled trial of outreach placement's effect on dental students' clinical confidence. J Dent Educ. 2006;70(5):566-570.

\section{Publish your work in this journal}

The Journal of Multidisciplinary Healthcare is an international, peerreviewed open-access journal that aims to represent and publish research in healthcare areas delivered by practitioners of different disciplines. This includes studies and reviews conducted by multidisciplinary teams as well as research which evaluates the results or conduct of such teams or

\section{Dovepress}

healthcare processes in general. The journal covers a wide range of areas and welcomes submission from practitioners at all levels, from all over the world. The manuscript management system is completely online and includes a very quick and fair peer-review system. Visit http://www.dovepress.com/testimonials.php to read real quotes from published authors. 